\title{
RESULTS FROM THE SECOND X-BAND RF GUN*
}

\author{
$\underline{\text { C. H. Ho }}^{\#}$, T. T. Yang, W. K. Lau, M. J. Horny, J. Y. Hwang, M. S. Yeh, Y. L. Tsai, SRRC \\ F. V. Hartmann, E. C. Landahl, H. A. Baldis, N.C.Luhmann, Jr., A. L. Troha, UC Davis
}

\section{Abstract}

A collaborative research effort between the Synchrotron Radiation Research Center (SRRC) and the UC Davis (UCD) is being put to improve the design and performance of the X-band $(8548 \mathrm{MHz})$ rf gun. The fabrication and cold test will be performed at SRRC. The high power test will be conducted at UC Davis. The cold test results are presented.

\section{INTRODUCTION}

A collaborative research effort for the development of the X-band photoinjector system has been formed between UC Davis and SRRC. Both the design and fabrication procedures have included separate verification from both groups [1]. The first X-band rf gun was fabricated, cold tested and brazed at SRRC and was delivered to UC Davis at the Lawrence Livermore National Laboratory (LLNL) site in April, 1997. The gun was installed and characterized by the research personnel from both groups [2], [3].

The first brazed X-band rf gun in 1997 had a few problems. The brazing joints between the various cavity components failed between the water cooling channel and the inner surface of the RF cavity. All cavity leaks were sealed with vacuum epoxy. External cooling was applied in the form of heat sink and copper tubing wound around the body of the accelerator cavity. Furthermore, the peak field ratio between the half cell and the full cell is out of balance. Fortunately, critical coupling of the Klystron signal corresponded to half-cell coupling. Critical coupling allowed the accelerator to be safely used as a resonant load from the Klystron despite this non-optimized condition. In addition, since the halfcell was energized, high-energy photoelectron production is still possible.

Therefore our goal for the second $\mathrm{X}$-band rf gun is aiming for correcting above deficiencies.

"Work supported in part by the National Science Council (Taiwan) under contract No. NSC88-2112-M-213-007, as well as by MURI (USA) under contract F49620-95-1-0253, by ATRI (USA) under contract F30602-94-2-0001, and by DoE (USA) under contract DE-FG0395ER54295.

${ }^{\#}$ Email: chh@srrc.gov.tw

\section{DESIGN AND FABRICATION}

Figure 1 shows the assembly drawing of the second Xband rf gun. Most of the design is the same as the first gun, except the cathode assembly.

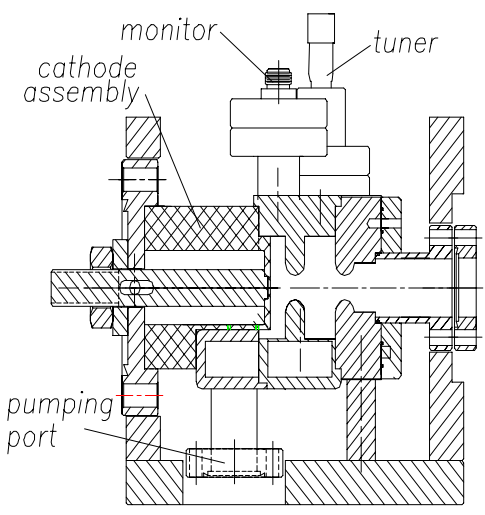

Figure 1: Assembly drawing of the gun system.

The cathode in the first gun is a choke type plunger with a large diameter of $20 \mathrm{~mm}$ to reduce the arcing problem from the gap between the cathode plug and cavity wall [1]. But it was found from the operation experience of the first gun that the resonant frequency becomes very sensitive to the cathode position. Therefore we prefer to braze a copper plate of $27.79 \mathrm{~mm}$ diameter to cover the end of the half cell $(27.63 \mathrm{~mm}$ diameter) and just use this plate as a fixed-position cathode. Figure 2 shows the drawing of the cathode assembly.

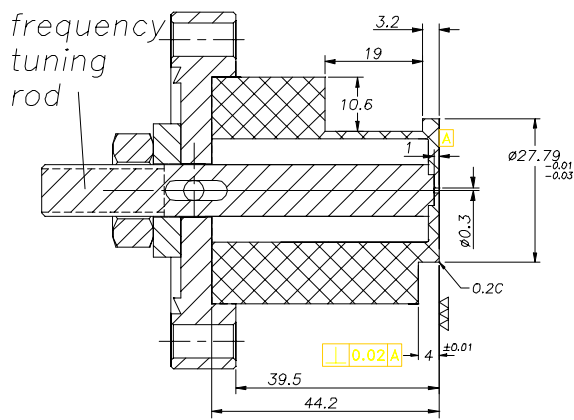

Figure 2: Drawing of the cathode assembly. 
From our previous brazing experiences, the resonant frequency may shift a lot and can not be corrected back by only using the tuner. Therefore we also brazed a frequency-tuning rod to the back of the cathode plate. The cathode plate can be deformed a little bit by the movement of tuning rod using a 2-arm gear puller. We certainly don't like to deform the cathode plate if not really necessary. This option will just save us from discarding the whole-brazed cavity set without any new experimental effort from high power test.

The cavity inner diameter was first enlarged to a little bit higher resonant frequency than the target frequency of $8548 \mathrm{MHz}$. Then the rf coupling irises are gradually enlarged to get close to the critical coupling. The final dimension of the cavity inner diameter is $27.63 \mathrm{~mm}$. The sizes of the two elliptical rf coupling irises on the half cell and the full cell are $3.0 \mathrm{~mm} \times 8.4 \mathrm{~mm}$ and $4.5 \mathrm{~mm} \times$ $8.4 \mathrm{~mm}$ respectively.

There is a frequency tuner and a field monitor on each cell. The tuner is a copper rod with $2.37 \mathrm{~mm}$ diameter. The maximum tuning range of the tuner is around +30 $\mathrm{MHz}$. The field monitor is a loop type monitor. It is made of a loop (50/50 Au/Cu alloy) attached to a commercial SMA coaxial feedthrough (ISI P/N 9252003). A Desktop Laser Welder EDW-25 (made by Equilasers Inc.) was used to weld the loop onto the SMA coax. The monitor is mounted on the cavity wall with a hole, which was gradually enlarged to $2 \mathrm{~mm}$ diameter for an appropriate transmission (S21) signal (around $-60 \mathrm{~dB}$ during cold test).

\section{COLD TEST RESULTS}

The experimental arrangement for the bead pull measurement is shown in Fig. 3.

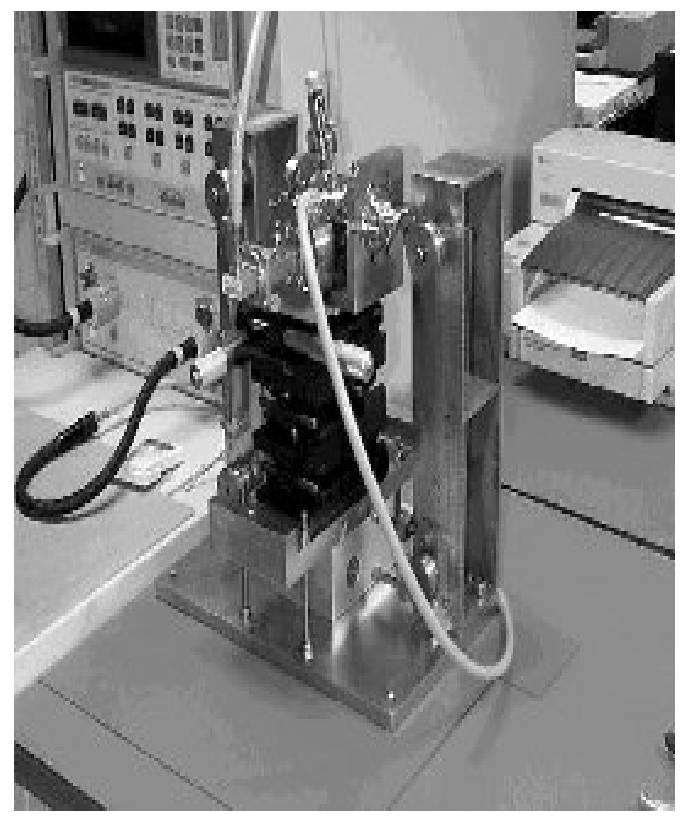

Figure 3: Bead pull measurement setup.
Two labs jacks were used to support and adjust the height of the gun body. One translator stage was used for the horizontal alignment and the other translator stage was used to move the gun body so that we were able to position the bead at any position along the longitudinal axis of the cavity. The movement resolution of the translator stage is $0.01 \mathrm{~mm}$, while we only move the gun body along the longitudinal axis in steps of $0.5 \mathrm{~mm}$.

Since the minimum mode separation between the $\pi$ mode and $\mathrm{O}$-mode is around $6 \mathrm{MHz}$ according to the URMEL-T prediction, the frequency perturbation from the bead should not be too large to break the coupling of both modes. A $0.83 \mathrm{~mm}$ length, $0.53 \mathrm{~mm}$ diameter metal cylinder, made from a section of a hypodermic needle was used as the perturbing bead, which gives around 1.5 $\mathrm{MHz}$ perturbation. An example bead pull measurement is shown in Figure 4 for a balanced field case.

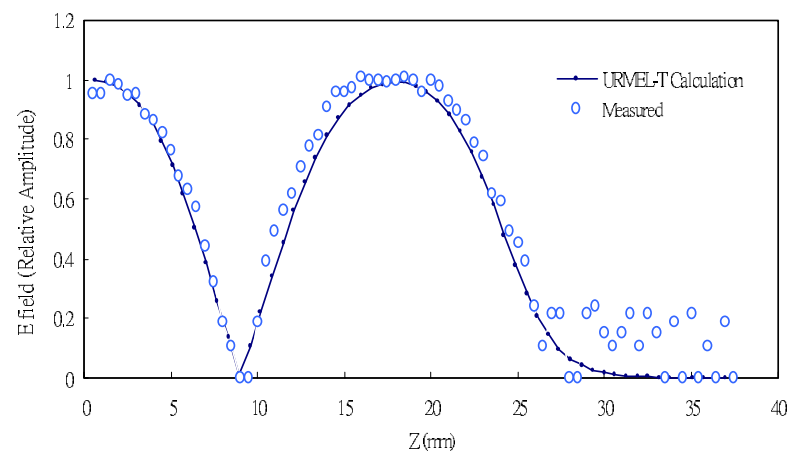

Figure 4: Longitudinal E-field distribution on axis.

The measured data also shows a good agreement with the URMEL-T calculation. We noticed the E-field goes to null at the beam iris position, which agrees with the distinct feature of the $\pi$-mode. The phase from field monitor ( $\mathrm{S}_{21}$ transmission signal) is also measured to look for 180 degrees phase difference, corresponding to the $\pi$ -mode. Figure 5 shows the reflected signal when the peak field ratio is 1.03 .

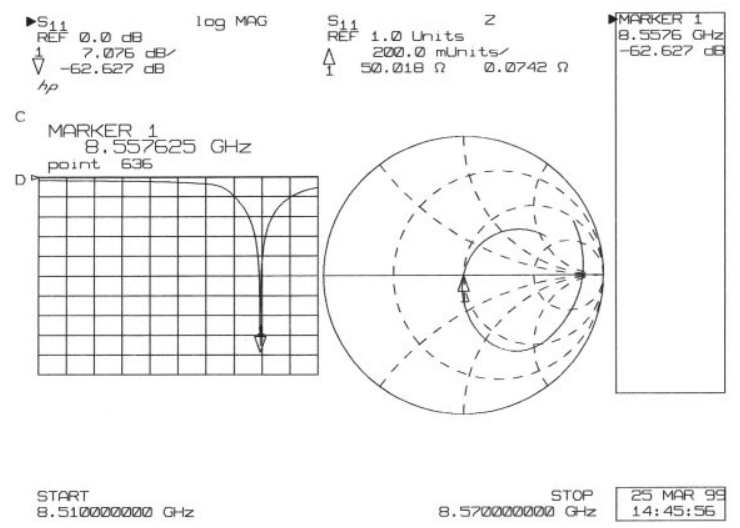

Figure 5: Reflection coefficient for the field ratio of 1.03. 


\section{SUMMARY}

An OFE copper cavity has been fabricated at SRRC for the second X-band rf gun. The dimensions of the cavity were optimized. The cold test results showed a promising balanced field case. All the cavity components had been fine polished and are going to be brazed very soon. We expect to begin the installation and high power test at UC Davis in late April, 1999.

\section{REFERENCES}

[1] C. H. Ho, W. K. Lau, T. T. Yang, J. Y. Hwang, S. Y. Hsu, Y. C. Liu, G. P. Le Sage, F. V. Hartemann, and N. C. Luhmann, Jr., "The Design and Fabrication of an X-Band RF Gun", AIP Conf. Proc. 398 for the Seventh Workshop on Advanced Accelerator Concepts (Lake Tahoe, California, 1996), p. 705.

[2] C. H. Ho, W. K. Lau, T. T. Yang, S. S. Chang, J. Y. Hwang, Y. C. Liu, G. P. Le Sage, F. V. Hartemann, and N. C. Luhmann, Jr., "The Construction and Initial high power test of an X-band rf gun", Proc. 1997 Particle Accelerator Conf. (Vancouver, B. C., Canada, 1997), p. 2858.

[3] E. C. Landahl, F. V. Hartemann, G. P. Le Sage, W. E. White, H. A. Baldis, C. V. Bennett, J. P. Heritage, N. C. Luhmann, Jr., and C. H. Ho, "Phase Noise Reduction and Photoelectron Acceleration in a High-Q RF Gun", IEEE Transactions on Plasma Science, Special Issue on High Power Microwave Generation, Vol. 26, No. 3, pp. 814-824 (June 1998). 